\title{
In situ Raman characterization of nanoparticle aerosols during flame synthesis
}

\author{
X. Liu • M.E. Smith · S.D. Tse
}

Received: 27 August 2009 / Revised version: 3 May 2010 / Published online: 15 June 2010

(C) Springer-Verlag 2010

\begin{abstract}
Raman spectroscopy is applied to diagnose nanoparticle presence and characteristics in a gaseous flow field. Specifically, in situ monitoring of the Raman-active modes of $\mathrm{TiO}_{2}$ and $\mathrm{Al}_{2} \mathrm{O}_{3}$ nanoparticles in aerosol form is demonstrated in high-temperature flame environments. This technique serves as a sensitive and reliable way to characterize particle composition and crystallinity (e.g. anatase versus rutile) and delineate the phase conversion of nanoparticles as they evolve in the flow field. The effect of temperature on the solid-particle Raman spectra is investigated by seeding nanoparticles into a co-flow jet diffusion flame, where local gas-phase temperatures are correlated by shape-fitting the $\mathrm{N}_{2}$ vibrational Stokes Q-branch Raman spectra. Applying the technique to a flame synthesis environment, the results demonstrate that in situ Raman of as-formed nanoparticles can be readily applied to other gas-phase synthesis systems, especially as an on-line diagnostic.
\end{abstract}

\section{Introduction}

Of the numerous techniques developed for the production of nanoparticles, one of the most popular methods is gasphase synthesis due to its high rate of synthesis, capability for continuous operation, and good control of particle size, crystallinity, and degree of agglomeration. Flame synthesis is a method that has drawn interest from a variety of research communities because of its potential for large-scale manufacture of a wide range of new materials $[1,2]$. However, it can be a complex chemical and physical transition process,

X. Liu · M.E. Smith · S.D. Tse $(\varangle)$

Department of Mechanical and Aerospace Engineering, Rutgers

University, 98 Brett Road, Piscataway, NJ 08854, USA

e-mail: sdytse@rci.rutgers.edu involving complicated aerodynamics, unknown precursor decomposition kinetics, fast chemical reactions, and multiple particle transport and growth processes. As a result, fundamental understanding of flame synthesis of nanostructured materials remains a major challenge, despite detailed study by a variety of scientific communities.

Utilization of advanced spectroscopic diagnostics enables non-intrusive in situ characterization of velocity, temperature, and chemical species concentration fields, along with nanoparticle composition and size, permitting fundamental understanding of the mechanisms of particle nucleation, growth, crystallization, and aggregation. This knowledge in turn affords the ability to define process conditions that enable repeatable, high-purity, and large yields of various nanomaterials.

Several laser-based spectroscopic diagnostics have been applied in situ to study flame synthesis, ranging from premixed to diffusion and from laminar to turbulent. For examples, laser-induced fluorescence (LIF) has been used to measure intermediate combustion and metalorganic precursor species (along with temperature), which play important roles in the transition from gas-phase monomers to solid-phase nanoparticles [3-5]. Spontaneous Raman scattering (SRS) has been employed to quantify major species concentration and temperature information [6-9]. Fourier transform infrared (FTIR) spectroscopy has been utilized to measure temperatures and concentrations of gases and particles [10]. Ultra-small-angle X-ray scattering (SAXS) has been applied to measure primary particle size by probing time-resolved scattering signatures of nanoparticles, even at volume fractions on the order of $10^{-6}$ [11]. Laser light scattering (LLS) has been used to measure fractal dimension, mean radius of gyration, aggregate size distribution, and local volume fraction of particles [12]. Laser-induced breakdown spectroscopy (LIBS) 
Fig. 1 Schematic of the in situ Raman scattering system. BS: beam splitter; L: lens; $M$ : mirror; PD: photodiode

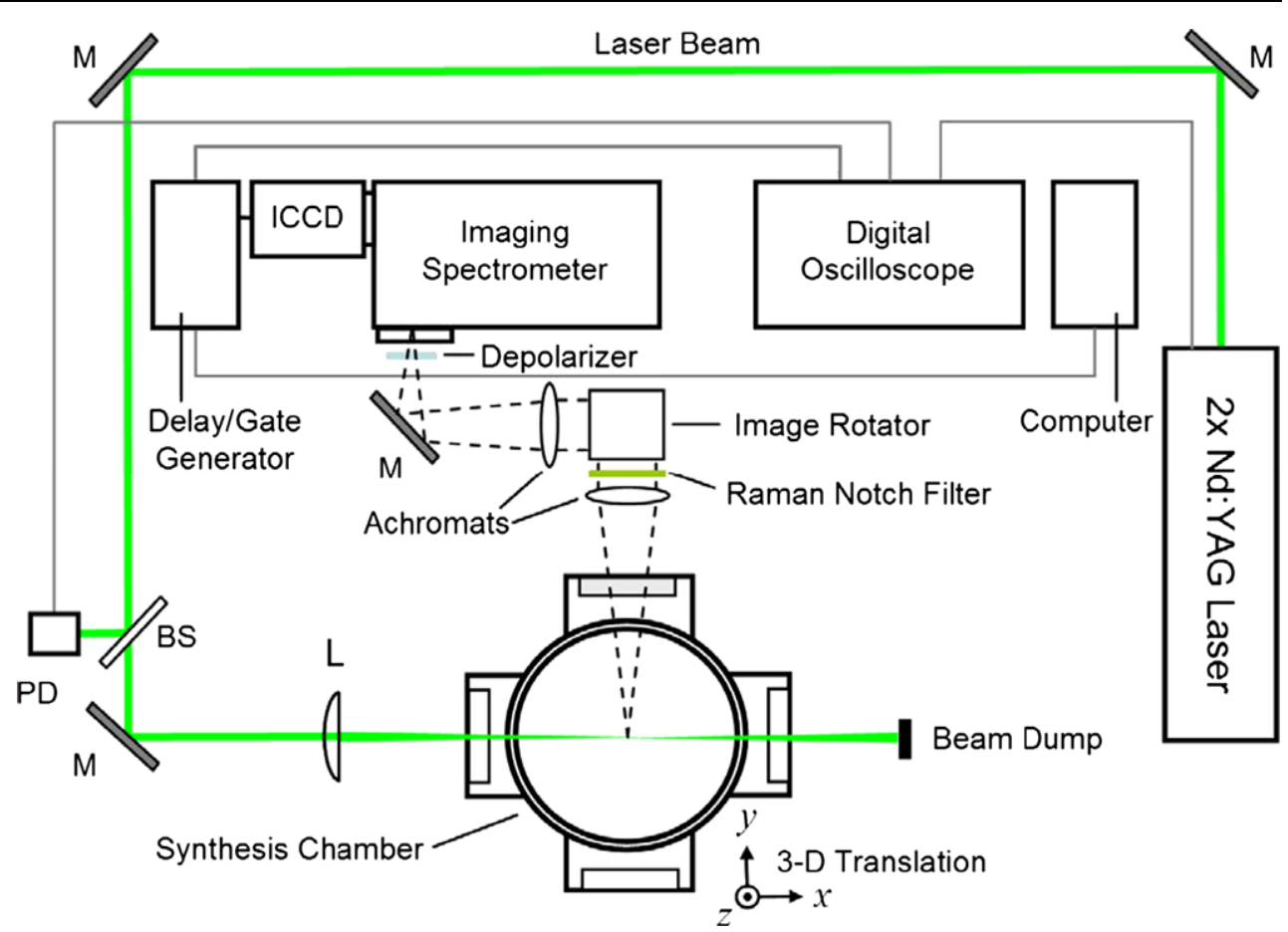

has been used to characterize particle composition [13], and laser-induced incandescence (LII) has been used to measure nanoparticle size [14]. By combining these techniques, many aspects of the synthesis process can be quantified. However, a technique to unambiguously identify an evolving nanoparticle's composition and crystallinity is still needed.

Raman spectroscopy is a robust technique that can characterize temperatures and concentrations of gases, liquids, solids, and, as will be shown, even multi-phase systems. Recent developments in instrumentation, i.e. intense laser sources, high-performance notch filters, and sensitive charge-coupled devices, have overcome many of the difficulties associated with the inherently weak Raman effect. Raman spectroscopy of thin films [15-18], nanopowders [19-24], and fullerenic materials [25, 26] are routinely performed using microscopy techniques with high spatial resolution. However, such characterization is performed ex situ; and various applications require in situ or real-time response (e.g. in industry process control [27]), remote sensing design [28], or other flexibilities. In this work, we introduce the novel application of Raman spectroscopy to characterize nanoparticle composition and crystallinity in aerosol form in high-temperature flame environments, particularly highlighting its utilization during gas-phase synthesis. Such a diagnostic is envisioned to become an indispensable tool in a production setting, where the properties of end-product materials can be verified (and optimized) during the run, prior to final collection.

\section{Experimental arrangement}

\subsection{In situ spontaneous Raman scattering setup}

Figure 1 shows a schematic of the spontaneous Raman scattering (SRS) system used to probe the experiments in situ. An injection-seeded frequency-doubled $(532 \mathrm{~nm}) \mathrm{Q}$-switch Nd:YAG laser (Quanta-Ray Lab-170, Spectra Physics) operating at $10 \mathrm{~Hz}(8.4 \mathrm{~ns}$ FWHM) serves as the excitation source. The laser beam is focused by a $300-\mathrm{mm}$ ( $500-\mathrm{mm}$ for the synthesis experiments) focal-length plano-convex fusedsilica lens to a probe volume with a waist diameter of approximately $200 \mu \mathrm{m}$. For gas-phase molecule excitation, the energy is $\sim 50 \mathrm{~mJ} /$ pulse; while for solid-phase nanoparticle excitation, the energy is attenuated to $\sim 6.5 \mathrm{~mJ} / \mathrm{pulse}$, due to the much stronger Raman signal. The scattered light from a $100 \mu \mathrm{m}$ diameter by $100 \mu \mathrm{m}$ length measuring volume is collected at $90^{\circ}$ by a $400-\mathrm{mm}$ focal-length achromat lens, passed through a Raman holographic notch filter (Kaiser HSPF-532.0-2.0), image rotated, depolarized, and focused by a $300-\mathrm{mm}$ focal-length achromat lens into a 0.5-m imaging spectrometer (Acton SpectraPro-500i, f/6.5) with a 2400 groove/mm holographic grating (Richardson, $68 \times 84 \mathrm{~mm}$, VIS) onto an ICCD detector (Princeton Instruments PIMAX 1300HQ-25-FO). The spectrometer magnification is unity, and the slit width is $75 \mu \mathrm{m}$, with a wavelength resolution of $\sim 0.04 \mathrm{~nm}$. The use of the pulsed laser source and gated detector improves the signal to noise ratio (SNR). For both gas-phase molecule and nanoparticle detection, typically 3000 shots, using a $100 \mathrm{~ns}$ gate width, are taken 
to increase SNR. The aerosol experiments are mounted on a 3-D translator, which allows spatial profiling with micrometer precision.

\subsection{Gas-phase SRS}

Spontaneous Raman spectroscopy is employed to determine local gas-phase temperatures at locations corresponding to nanoparticle detection, for atmospheric flame experiments. The temperature measurements are obtained by leastsquares fitting [29] the shape of the Q-branch $\mathrm{N}_{2}$ Raman spectrum (Raman shift of $2330 \mathrm{~cm}^{-1}$ ) to a library of theoretical spectra [30] spaced $50 \mathrm{~K}$ apart. The uncertainty in the fitted temperature is less than $\pm 50 \mathrm{~K}$, and the reproducibility of the measurements is within $\pm 20 \mathrm{~K}$.

\subsection{Nanoparticle SRS}

Solid-phase Raman scattering shares many common features with gas phase from the basic principles to the experimental setups. Raman spectroscopy has been used for the in situ determination of the chemical composition of multicomponent microparticles, with the techniques not much different from those used for bulk material [31]. For titania, Raman spectroscopy has been carried out by various investigations [15, 20, 21, 32-35]. Titania has 3 main polymorphs, i.e. anatase (tetragonal), rutile (tetragonal), and brookite (orthorhombic). For anatase single crystal, Ohsaka [36] detected the six Raman-active modes from factor group analysis, identifying them at $144 \mathrm{~cm}^{-1}\left(\mathrm{E}_{\mathrm{g}}\right)$, $197 \mathrm{~cm}^{-1}\left(\mathrm{E}_{\mathrm{g}}\right), 399 \mathrm{~cm}^{-1}\left(\mathrm{~B}_{1 \mathrm{~g}}\right), 513 \mathrm{~cm}^{-1}\left(\mathrm{~A}_{1 \mathrm{~g}}\right), 519 \mathrm{~cm}^{-1}$ $\left(\mathrm{B}_{1 \mathrm{~g}}\right)$, and $639 \mathrm{~cm}^{-1}\left(\mathrm{E}_{\mathrm{g}}\right)$. For rutile single crystal, Porto et al. [37] detected the four Raman-active modes, identifying them at $143 \mathrm{~cm}^{-1}\left(\mathrm{~B}_{1 \mathrm{~g}}\right), 447 \mathrm{~cm}^{-1}\left(\mathrm{E}_{\mathrm{g}}\right), 612 \mathrm{~cm}^{-1}$ $\left(\mathrm{A}_{1 \mathrm{~g}}\right)$, and $826 \mathrm{~cm}^{-1}\left(\mathrm{~B}_{2 \mathrm{~g}}\right)$. Although the $143 \mathrm{~cm}^{-1}\left(\mathrm{~B}_{1 \mathrm{~g}}\right)$ peak overlaps with anatase, Ref. [15] finds it to be extremely small for rutile, especially in relation to the other peak heights and thus should not be of concern in discriminating between anatase and rutile phases. Little information exists for brookite, which is not investigated in this work. Other works have found that the distinguishing phonon frequencies in single-crystal Raman spectra are similar to those in the spectra of polycrystalline [38-40] and nanophase [41] materials, such that all the Ramanactive modes can be associated (albeit with slight shifts) to that for the single-crystal spectra [20]. In this work, the Raman modes in $\mathrm{TiO}_{2}$ (and $\mathrm{Al}_{2} \mathrm{O}_{3}$ ) nanoparticles are referenced to those reported in the literature for the bulk phase.

Alumina has several crystalline phases. $\gamma-\mathrm{Al}_{2} \mathrm{O}_{3}$, with $F d \overline{3} m$ space group (cubic), does not have Raman modes [42]. Yet, $\alpha-\mathrm{Al}_{2} \mathrm{O}_{3}$ (corundum), the equilibrium phase, with $R 3 c$ space group (rhombohedral), gives rise to seven Ramanactive phonon modes, $2 \mathrm{~A}_{1 \mathrm{~g}}+5 \mathrm{E}_{\mathrm{g}}$ [43], i.e., $378 \mathrm{~cm}^{-1}\left(\mathrm{E}_{\mathrm{g}}\right)$,
$418 \mathrm{~cm}^{-1}\left(\mathrm{~A}_{1 \mathrm{~g}}\right), 432 \mathrm{~cm}^{-1}\left(\mathrm{E}_{\mathrm{g}}\right), 451 \mathrm{~cm}^{-1}\left(\mathrm{E}_{\mathrm{g}}\right), 578 \mathrm{~cm}^{-1}$ $\left(E_{g}\right), 648 \mathrm{~cm}^{-1}\left(A_{1 g}\right)$, and $755 \mathrm{~cm}^{-1}\left(E_{g}\right)$. This Raman signature of $\alpha-\mathrm{Al}_{2} \mathrm{O}_{3}$ has been used to detect the transformation of $\gamma-\mathrm{Al}_{2} \mathrm{O}_{3}$ to $\alpha-\mathrm{Al}_{2} \mathrm{O}_{3}$ in laser treatment of as-sprayed coatings [44].

In this work, Raman particle scatter is targeted by using a low excitation power, purposely relegating the much weaker Raman gas-phase scatter to the instrumental detection threshold. It is worth noting that in all of our studies, we examine the Stokes Raman spectra.

\section{Validation and calibration of technique}

3.1 Ex situ $\mathrm{TiO}_{2}$ nanoparticle characterization on glass slides at room temperature

The capability of the optical arrangement of our in situ Raman setup (Fig. 1) to characterize nanopowders is validated by comparing its performance to that of a commercial $\mathrm{Ra}$ man microscope for static nanoparticles on a glass slide. Figure 2 displays the setup for the slide configuration. The excitation power is kept under $2 \mathrm{~mJ} /$ pulse and is monitored using a power meter. Specular reflection is eschewed by adjusting the angle of the glass slide (see Fig. 2) so that only diffuse scatter from the nanopowder is collected by the Raman system.

Figure 3(a) shows a high-SNR Raman spectrum of anatase $\mathrm{TiO}_{2}$ nanopowder produced by our system, without any background subtraction or smoothing. As can be seen, the spectrum is a combination of two smaller coverage spectra, centered at $350 \mathrm{~cm}^{-1}$ and $500 \mathrm{~cm}^{-1}$, due to the use of a $2400 \mathrm{~g} / \mathrm{mm}$ grating for high resolution. The main Raman peaks are those for anatase at $145 \mathrm{~cm}^{-1}\left(\mathrm{E}_{\mathrm{g}}\right)$, $397 \mathrm{~cm}^{-1}\left(\mathrm{~B}_{1 \mathrm{~g}}\right), 516 \mathrm{~cm}^{-1}\left(\mathrm{~A}_{1 \mathrm{~g}}+\mathrm{B}_{1 \mathrm{~g}}\right)$, and $639 \mathrm{~cm}^{-1}\left(\mathrm{E}_{\mathrm{g}}\right)$. The same nanopowder-coated glass slide is tested with a Renishaw inVia Raman microscope with 785-nm excitation; and the spectrum is shown in Fig. 3(b), with Raman peaks at $146 \mathrm{~cm}^{-1}\left(\mathrm{E}_{\mathrm{g}}\right), 398 \mathrm{~cm}^{-1}\left(\mathrm{~B}_{1 \mathrm{~g}}\right), 516 \mathrm{~cm}^{-1}\left(\mathrm{~A}_{1 \mathrm{~g}}+\mathrm{B}_{1 \mathrm{~g}}\right)$, and $639 \mathrm{~cm}^{-1}\left(\mathrm{E}_{\mathrm{g}}\right)$. As reference, Fig. 3(b) also displays the known spectra for anatase and rutile for film samples as given in Ref. [45]. The main Raman peaks detected using our in situ setup and the Raman microscope agree very well with each other, substantiating the competence of our system to characterize nanoparticles with high-quality spectra. Although the Raman peak at $197 \mathrm{~cm}^{-1}\left(\mathrm{E}_{\mathrm{g}}\right)$ is discernible by our system, it is more evident in the microscope system. Background subtraction would have better resolved this peak. Nevertheless, this peak is characteristically small and is not necessary to be resolved to verify the anatase phase, as shown in other works $[20,41]$. 
Fig. 2 Schematic of the setup for the nanopowder on glass slide calibration configuration
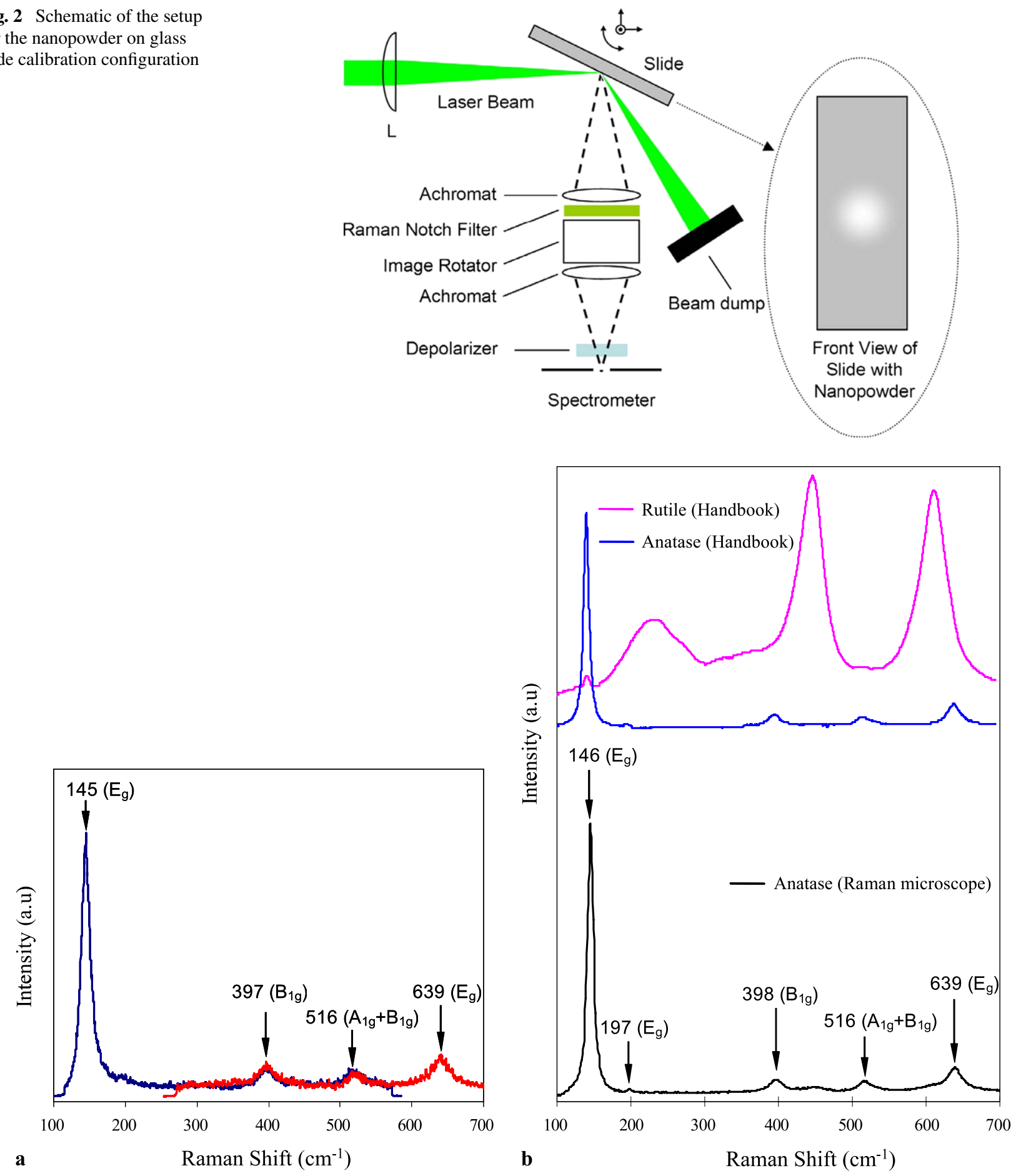

Fig. 3 Raman spectrum of anatase titania on a glass slide: a taken using our in situ Raman setup. Spectrum is composed of two smaller coverage spectra, with the grating centered at $350 \mathrm{~cm}^{-1}$ and $500 \mathrm{~cm}^{-1}$; b taken using Renishaw inVia Raman microscope. Known spectra of anatase and rutile films given in Ref. [45] are also shown

\subsection{In situ aerosol characterization}

\subsubsection{Setup of nanoparticle-seeded calibration flame}

The Raman spectroscopy of 40-nm $\mathrm{TiO}_{2}$ nanoparticles seeded into a co-flow jet diffusion flame is investigated to demonstrate the ability of our system to characterize nanoaerosols, as well as to study temperature and species interference effects on the collected spectra. The schematic in Fig. 4 displays the burner and the supporting gas-flow instrumentation producing the jet diffusion flame. The burner is 


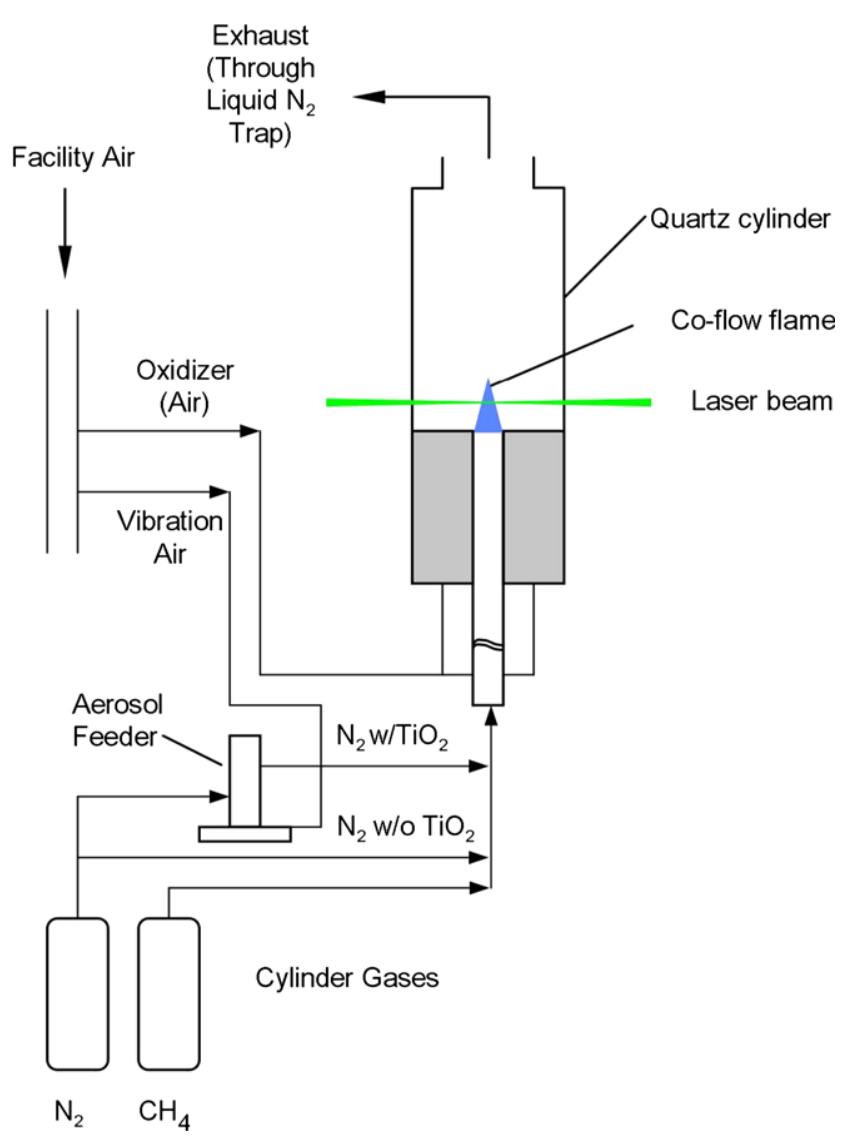

Fig. 4 Schematic of the setup for the nanoparticle-seeded co-flow jet diffusion flame

composed of a center tube surrounded by a concentric outer annulus, which is filled with 3-mm glass beads to distribute an airflow that exits the burner through a ceramic honeycomb with a flat velocity profile. Nitrogen-diluted methane flows through the center tube, which is sufficiently long to produce a fully-developed laminar velocity profile at the burner exit. Nanoparticles are injected into this center tube. A quartz cylinder encompasses the flame and flow field to isolate the aerosol from the ambient surroundings. Raman measurement of the $\mathrm{TiO}_{2}$ nanoparticles is examined along the axial centerline (proceeding downstream of the burner exit) of the axi-symmetric flow field. At the same locations where $\mathrm{TiO}_{2}$ Raman signals are taken, $\mathrm{N}_{2}$ Raman spectra are also collected to determine the local gas-phase temperatures.

As seen from Fig. 4, the gas-flow system comprises an $\mathrm{N}_{2}$ line which bypasses the aerosol feeder, so that conditions can be examined sans nanoparticle seeding while maintaining the same flow rate and thus flame state. By comparing Raman spectra with and without the presence of $\mathrm{TiO}_{2}$ nanoparticles, gas-phase temperatures can be crossvalidated; and interference modes can be identified and accounted for. For example, the low-frequency $\mathrm{N}_{2}$ rotational Raman spectra and the low-frequency $\mathrm{E}_{\mathrm{g}}$ mode of $\mathrm{TiO}_{2}$ are both found in the same Raman shift range of 100 to $200 \mathrm{~cm}^{-1}$.

\subsubsection{Results and discussion}

Measurements are taken at points with a $2.5-\mathrm{mm}$ interval along the axial centerline of the flame. As previously mentioned, the Q-branch of the $\mathrm{N}_{2}$ vibrational Raman spectra at these points are also obtained and used to determine the gas-phase temperatures.

For the $\mathrm{TiO}_{2}$ nanoparticle Raman investigations, a very low feeding rate of the $\mathrm{TiO}_{2}$ nanopowder is used to approximate the conditions in the flame synthesis environment (described later). A low particle density $\left(\sim 10^{17}\right.$ particles $\left./ \mathrm{m}^{3}\right)$ precludes heavy interference of the particles, facilitating analysis. As will be seen, under the current experimental situation, the SNR is sufficient to recognize coexisting rutile and anatase content in the particles. Background luminosity can be reduced by gating (on the order of $10^{6}$ with a $100 \mathrm{~ns}$ detection window), and broadband fluorescence from flame species can be corrected for based on empirically determined characteristics [46]. For the low-frequency $\mathrm{E}_{\mathrm{g}}$ mode of $\mathrm{TiO}_{2}$, interference from the $\mathrm{N}_{2}$ rotational $\mathrm{Ra}$ man modes can exist. Figure 5 shows a typical $\mathrm{N}_{2}$ rotational spectrum for our flame when no particles are present. However, such gas species spectra can be easily subtracted out by using the "clean" (without $\mathrm{TiO}_{2}$ powder) $\mathrm{N}_{2}$ bypass line (Fig. 4) to obtain the "background" gas-phase spectra.

Another consideration in taking Raman spectra for aerosols is that photons may randomly 'diffuse' by scattering at particle boundaries and then reemerge to be detected with a delay [47]. In the current study, such a response is observed for the $\mathrm{TiO}_{2}$ nanoparticle aerosol. In contrast to the $<50$ ns gate width that we generally need for our laserpulse-synchronized ICCD camera to detect the Raman signal from gas molecules, a longer gating interval of 100 to $200 \mathrm{~ns}$ is required for the detection of nanoparticles, implying that inter-powder diffusion extends the lifetime of the Raman scattering signal. Further study is needed to explore this effect as a function of nanoparticle concentration, size, and composition.

A sequence of processed in situ $\mathrm{TiO}_{2}$ Raman spectra of the anatase nanoparticles seeded into the diffusion flame, at different distances along the axial centerline from the burner exit, is given in Fig. 6. Near the burner exit, at relatively low temperatures (points $a$ and $b$ ), very strong peaks at $\sim 150 \mathrm{~cm}^{-1}\left(\mathrm{E}_{\mathrm{g}}\right), \sim 407 \mathrm{~cm}^{-1}\left(\mathrm{~B}_{1 \mathrm{~g}}\right), \sim 528 \mathrm{~cm}^{-1}$ $\left(\mathrm{A}_{1 \mathrm{~g}}+\mathrm{B}_{1 \mathrm{~g}}\right)$, and $\sim 645 \mathrm{~cm}^{-1}\left(\mathrm{E}_{\mathrm{g}}\right)$ indicate the dominance of the anatase phase. The temperature dependence of the lowest $E_{g}$ mode manifests itself as a red shift (as defined for the Stokes regime) from $145 \mathrm{~cm}^{-1}$, at room temperature $(300 \mathrm{~K})$ from the glass slide measurement to $150 \mathrm{~cm}^{-1}$, at elevated temperatures within the flame (e.g. 664 and $763 \mathrm{~K}$, points a 
Fig. 5 Typical $\mathrm{N}_{2}$ rotational Raman spectrum detected in situ in the co-flow jet diffusion flame without $\mathrm{TiO}_{2}$ nanoparticle seeding
Fig. 6 In situ Raman spectra of seeded $\mathrm{TiO}_{2}$ nanoparticles flowing through the co-flow jet diffusion flame, along the axial centerline at different heights above the burner exit. Gas-phase temperature is given and made by SRS on $\mathrm{N}_{2}$. Figure shows the transformation from anatase to rutile of the originally anatase seeded nanoparticles
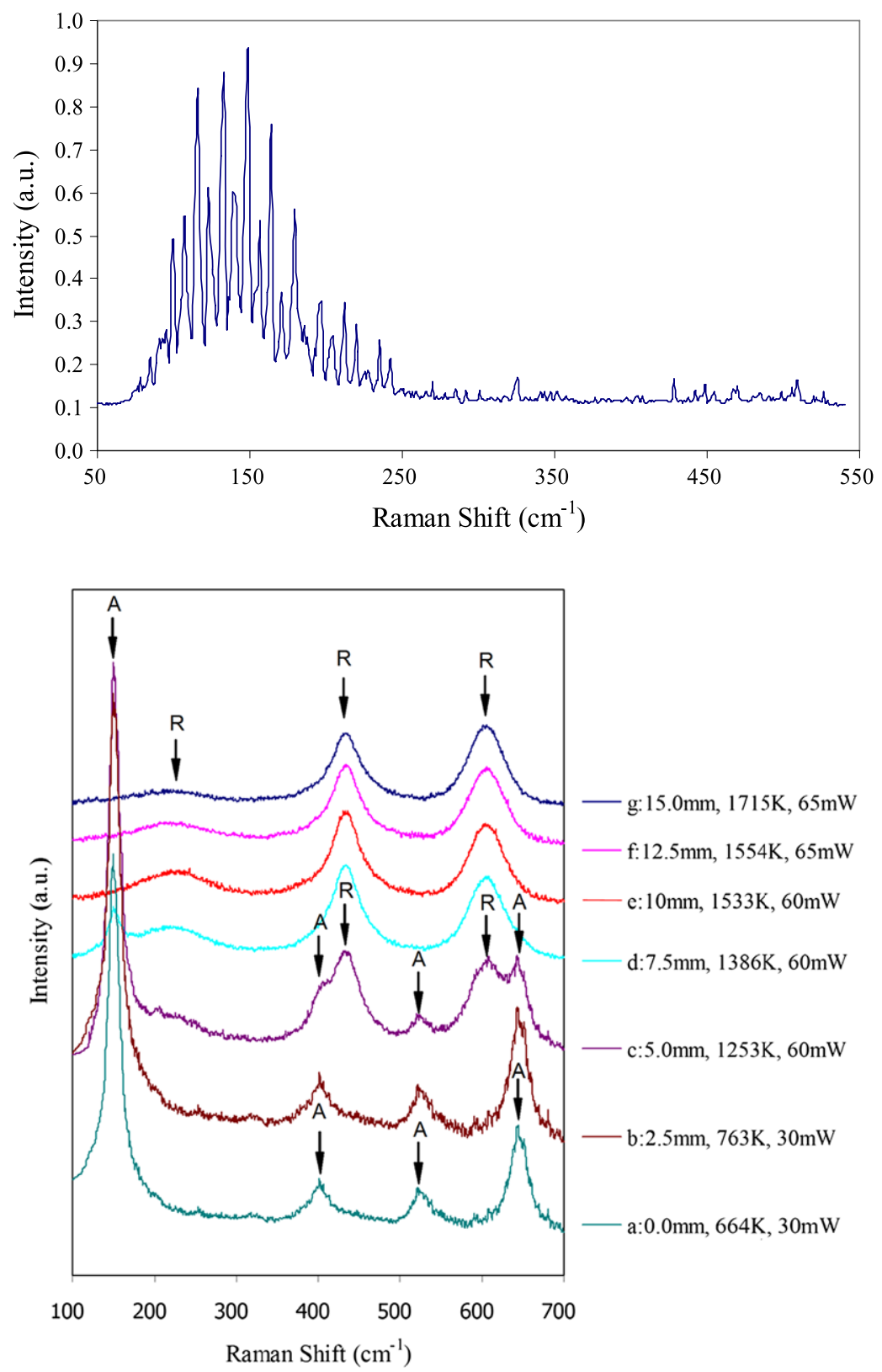

and b). A combination of size confinement and anharmonic effects likely contribute to red shifting and broadening of the spectral peaks [22]. References [21] and [48] found red shifting (as defined for the Stokes regime) of the peaks with decreasing particle size, due to phonon confinement. At high temperatures, however, the anharmonic effect was found to be more prominent [22].

Above $1000 \mathrm{~K}$, a phase transition from anatase to rutile is revealed in the Raman spectra. As seen in Fig. 6 at point c, the $\sim 150 \mathrm{~cm}^{-1}\left(\mathrm{E}_{\mathrm{g}}\right)$ peak has decreased greatly; and new broad peaks at $\sim 440 \mathrm{~cm}^{-1}\left(\mathrm{E}_{\mathrm{g}}\right)$, and $\sim 617 \mathrm{~cm}^{-1}\left(\mathrm{~A}_{1 \mathrm{~g}}\right)$ appear that are comparable in height with the $150 \mathrm{~cm}^{-1}$ peak, along with the previous anatase peaks. The new peaks correspond to the well-known Raman spectra of rutile, reported as $447 \mathrm{~cm}^{-1}\left(\mathrm{E}_{\mathrm{g}}\right)$ and $612 \mathrm{~cm}^{-1}\left(\mathrm{~A}_{1 \mathrm{~g}}\right)$ in Ref. [37] (see Fig. 3(b)). Again, the redshift for these two peaks are mainly due to the elevated temperature effect. From points $\mathrm{d}$ to $\mathrm{g}$, the nanoparticles are now rutile. In addition, there exists a strong broad band at $\sim 235 \mathrm{~cm}^{-1}$ (which cannot be assigned to fundamental modes allowed by symmetry in the rutile phase [37]) that is consistent with what others have found for heated $\mathrm{TiO}_{2}$ powders (see Fig. 3(b)) that mark the anatase-rutile transformation [37, 39, 40]. Porto et al. [37] ascribed it to a combination band; Hara and Nicol [39] proposed that it is disorder-induced; and Blachandran et al. [40] suggested that it is due to the second-order scat- 
Fig. 7 In-situ Raman spectra of seeded $\mathrm{Al}_{2} \mathrm{O}_{3}$ nanoparticles flowing through the co-flow jet diffusion flame, along the axial centerline at two heights above the burner exit. Gas-phase temperature is given and made by SRS on $\mathrm{N}_{2}$. Figure shows the transformation from $\gamma$-alumina (no Raman signature) to $\alpha$-alumina of the originally $\gamma$-alumina seeded nanoparticles

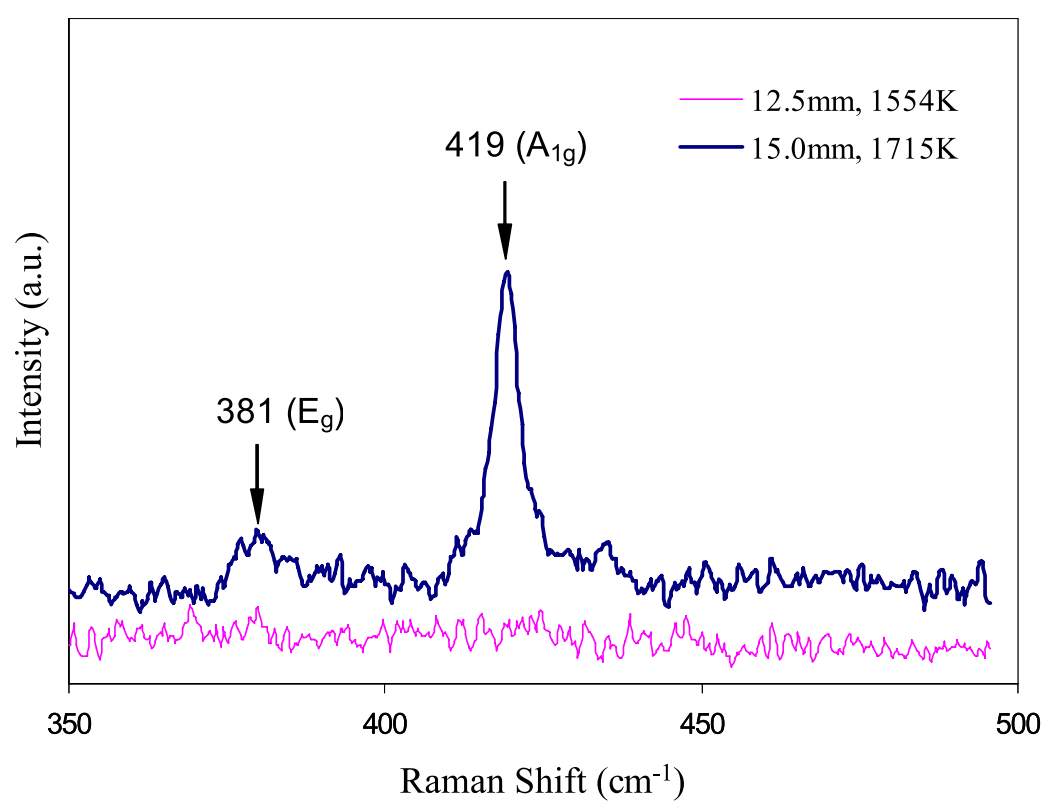

tering from a multiphonon process. Nonetheless, the entire Raman-spectra sequence of Fig. 6 evinces the phase transformation of $\mathrm{TiO}_{2}$ nanoparticle due to in-flight heat treatment from the hot flame. The measurements indicate the suitability of the technique to monitor and characterize $\mathrm{TiO}_{2}$ nanoparticle formation from metalorganic precursors during gas-phase synthesis, which is discussed in the next section.

To extend and generalize the capability of using Raman scattering to characterize aerosol particles in situ, 100$\mathrm{nm} \gamma-\mathrm{Al}_{2} \mathrm{O}_{3}$ nanoparticles are examined by feeding them into the diffusion flame. From the spectra (Fig. 7), $\alpha$ $\mathrm{Al}_{2} \mathrm{O}_{3}$ is detected at a gas-phase temperature of $1715 \mathrm{~K}$ at $h=15 \mathrm{~mm}$. Given the high heat transfer coefficient ( $\sim 10^{6} \mathrm{~W} / \mathrm{m} \mathrm{K}$ ) for our nano-sized particles and flame conditions, the particle temperatures should be very close to that of the local gas. The residence time of a particle traveling along the axial centerline from the exit of the burner to the tip of the flame (a $15 \mathrm{~mm}$ distance) is $\sim 45 \mathrm{~ms}$. Thus, with the in situ Raman technique revealing the instantaneous phase transition, kinetic studies can be made of such transformations as explicit functions of time and temperature. Verification of particle-gas temperature equilibrium may be possible by directly measuring the particle temperature using spontaneous Raman spectroscopy. Scepanovic et al. [22] studied the temperature dependence of the first $\mathrm{E}_{\mathrm{g}}$ Raman mode of $\mathrm{TiO}_{2}$ nanopowder prepared by laser-induced pyrolysis, where the local temperature (with uncertainties of $\pm 100 \mathrm{~K}$ ) was determined by the Stokes/anti-Stokes intensity ratio of the first $E_{g}$ mode of particles themselves. This technique of probing nanoparticle temperatures in an aerosol is the subject of on-going work.

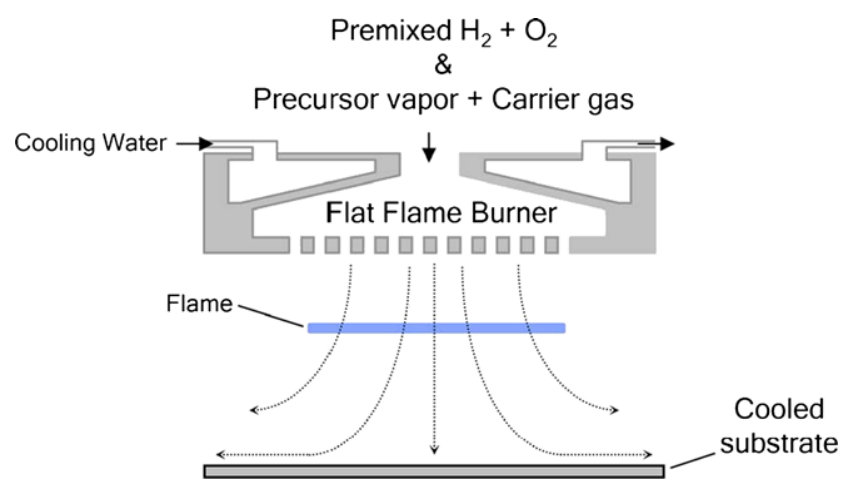

Fig. 8 Schematic of the axisymmetric, stagnation-point premixed flame synthesis setup

\section{Application of technique to flame synthesis of nanoparticles}

\section{1 $\mathrm{TiO}_{2}$ nanoparticle synthesis flame setup}

Figure 8 displays the low-pressure flame synthesis setup. The axisymmetric, stagnation-point premixed flame is formed by flowing premixed reactants, added with chemical precursor vapor, through a flat-flame burner impinging onto a cold substrate. Liquid precursor (i.e. titanium tetra-isopropoxide (TTIP)) is vaporized and entrained into a carrier gas via a heated bubbling unit and then combined with combustible premixed gases (e.g. hydrogen/oxygen) and delivered to the burner. The flow system is metered with mass flow controllers, and the flow lines are heated (and temperature controlled) to prevent precursor condensation. The chemical precursors pyrolyze and oxidize in the flame and condense into nanoparticles as the gases advect toward the cool substrate. 
Fig. 9 In situ Raman spectra of $\mathrm{TiO}_{2}$ nanoparticles formed during low-pressure premixed flame synthesis (see Fig. 8), along the axial centerline at different distances from the substrate $(0 \mathrm{~mm})$. Burner exit is located at $40 \mathrm{~mm}$. Gas-phase temperature is given and made by LIF on $\mathrm{OH}$. Figure shows the increasing anatase content as the nanoparticles approach the substrate

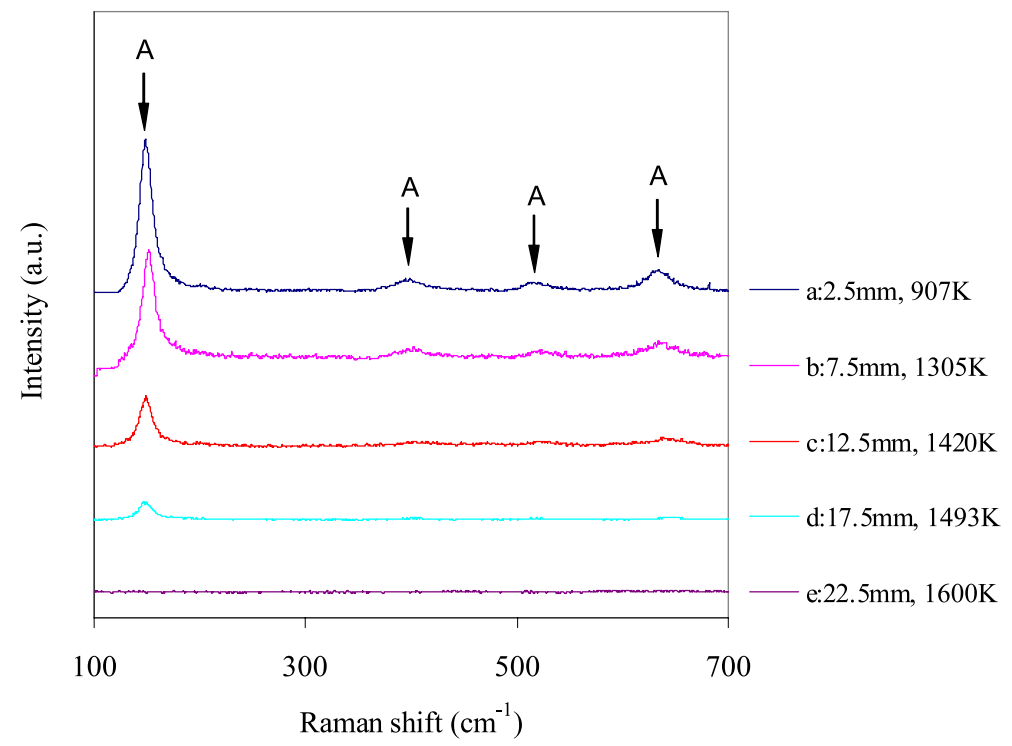

The synthesis reactor (see Fig. 1) consists of a $47-\mathrm{cm}$ diameter cold-wall vacuum chamber, which is maintained at the desired pressure by a roughing pump, throttle valve, and closed-loop pressure controller. Inside the chamber, the burner and substrate are fixed at a set distance apart. Both the burner and substrate are water-cooled, and their temperatures are monitored with K-type thermocouples. The chamber is configured with four orthogonal quartz view ports for optical access, and the entire chamber is mounted to a 3-axis positioner to enable spatial mapping of the aerosol flow field by laser-based diagnostics.

Given the weakness of the gas-phase Raman scattering signal at low pressures, the flame structure is probed in situ using two-line laser-induced fluorescence (LIF) of the hydroxyl radical generated innately by the flame reactions to determine the gas-phase temperature distributions along the axial centerline. Nevertheless, the weak gas-phase Raman scatter under these low-pressure, high-temperature (resulting in very low density) conditions aid in isolating particle Raman scattering. Simulation of the gas-phase flame structure of our quasi-one-dimensional flow field using detailed chemical kinetics and transport is performed using the Sandia SPIN code. By comparing the simulation with measurement, the nature of the material processing flow field is revealed. Further details can be found in Refs. [4, 5]. Moreover, a sectional model, coupled with the simulated flow field and flame structure, is employed to model particle growth dynamics, computing aggregate and primary particle size distribution, geometric standard deviation, and average primary particle size. The computations are compared with the experiments, for which in situ characterization of the nanoparticles in the flow field is accomplished by a low-pressure aerosol sampling system connected to a nano-scanning mobility particle sizer, as well as by TEM sampling.
The flames examined in this study use premixed hydrogen and oxygen with an equivalence ratio of $\sim 0.42$, mass flux of $2.519 \mathrm{mg} / \mathrm{s} / \mathrm{cm}^{3}$, and a system of pressure of 20 torr. For titania synthesis, a precursor loading rate of $7.185 \times 10^{-4} \mathrm{~mol} / \mathrm{min}$ of TTIP is used.

\subsection{Results and discussion}

A sequence of in situ Raman spectra obtained along the centerline of the gas-synthesis flow field is presented in Fig. 9. The local gas-phase temperatures are determined using twoline LIF of $\mathrm{OH}$ and confirmed with numerical simulation using detailed chemical kinetics and transport. Here, particle temperatures are expected to be close to gas-phase temperatures, as the particles are homogeneously formed and grow mainly through coalescence and coagulation [5]. Particles with anatase characteristics are first detected about midway between the burner and the substrate (see point d of Fig. 9). As evinced, the strong $E_{\mathrm{g}}$ Raman peak at $\sim 150 \mathrm{~cm}^{-1}$ (red shifted in the Stokes regime due to the previously-discussed temperature and phonon confinement effects) provides a good indication of the anatase phase, along with confirming peaks at $399 \mathrm{~cm}^{-1}\left(\mathrm{~B}_{1 \mathrm{~g}}\right), 513 \mathrm{~cm}^{-1}\left(\mathrm{~A}_{1 \mathrm{~g}}+\mathrm{B}_{1 \mathrm{~g}}\right)$, and $639 \mathrm{~cm}^{-1}\left(\mathrm{E}_{\mathrm{g}}\right)$. All the same, we are not using the shifts to determine either temperature or particle size. Instead, we analyze the Raman peaks to establish crystalline nature and particle composition, so, as long as the peaks can be associated with identifying features of a particular polymorph, then any minor shift is immaterial. As shown, the peaks become stronger and more distinct near the substrate (e.g. point a of Fig. 9). In fact, the small $\mathrm{E}_{\mathrm{g}}$ peak at $\sim 200 \mathrm{~cm}^{-1}$ is visible here. This favorable spectrum endorses our technique since the nanopowder collected at the substrate is characterized post-experiment as anatase using both XRD and Raman. Additionally, in situ TEM sampling at locations near 
Fig. 10 Elastic laser light scattering from nanoparticles synthesized in the flame, as a function of distance from the substrate. Burner exit is located at $4 \mathrm{~cm}$. A relative number density is computed using nano-SMPS data for the aggregate particle size

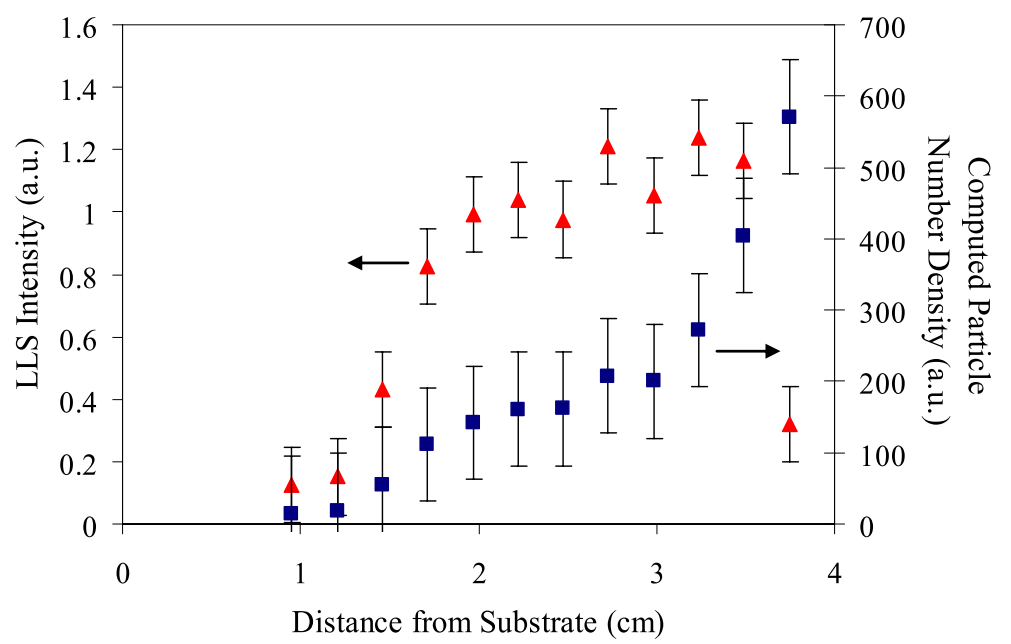

The agreeing sectional model and nano-SMPS results, along with the LLS data, suggest that significant TTIP decomposition and nanoparticle formation occurs near the burner at the beginning of the flow field. However, as mentioned above, the in situ Raman spectra of $\mathrm{TiO}_{2}$ nanoparticles in Fig. 9 do not divulge anatase phases within the $\mathrm{TiO}_{2}$ nanoparticles until half way to the substrate, with increasing crystallinity upon approaching it. Therefore, although nanoparticle nucleation occurs almost from the beginning, the synthesized nanoparticles are either suboxidic with no Raman signature or amorphous. Amorphous particles are formed very fast, explaining the sharp rise in LLS (Fig. 10) intensity near the burner exit. However, the particles are not identifiable by Raman spectroscopy, until they experience the transformation to crystalline form. Anatase crystallization kinetics is a relatively fast process at low temperature [49], which has been shown to take $12-30 \mathrm{~ms}$ in our flame synthesis system [5]. Figure 11 plots computed particle residence time, along with temperature, as a function of location between the substrate and burner. It is seen that $12 \mathrm{~ms}$ particle residence time for our synthesis condition corresponds to a location of $\sim 5 \mathrm{~mm}$ from the substrate. This finding is in accord with the Raman data of Fig. 9, where full anatase crystallization is shown to occur within $\sim 7.5 \mathrm{~mm}$ of the substrate. Furthermore, as expected, rutile is excluded in our synthesis condition, unlike that for the particle-seeded diffusion flame used for validation. Formation of rutile from anatase requires about one second of residence time at $1473 \mathrm{~K}$ [50]. Consequently, the low temperature history and the short characteristic residence time (12-30 ms) in this flame synthesis condition are the reasons for the absence of rutile and the dominance of anatase. As evidenced, our in situ Raman technique captures properly the crystallization progress of synthesized nanoparticles inflight during flame synthesis (Fig. 9). 
Fig. 11 Computed particle residence time and temperature between the substrate and burner $(4 \mathrm{~cm})$

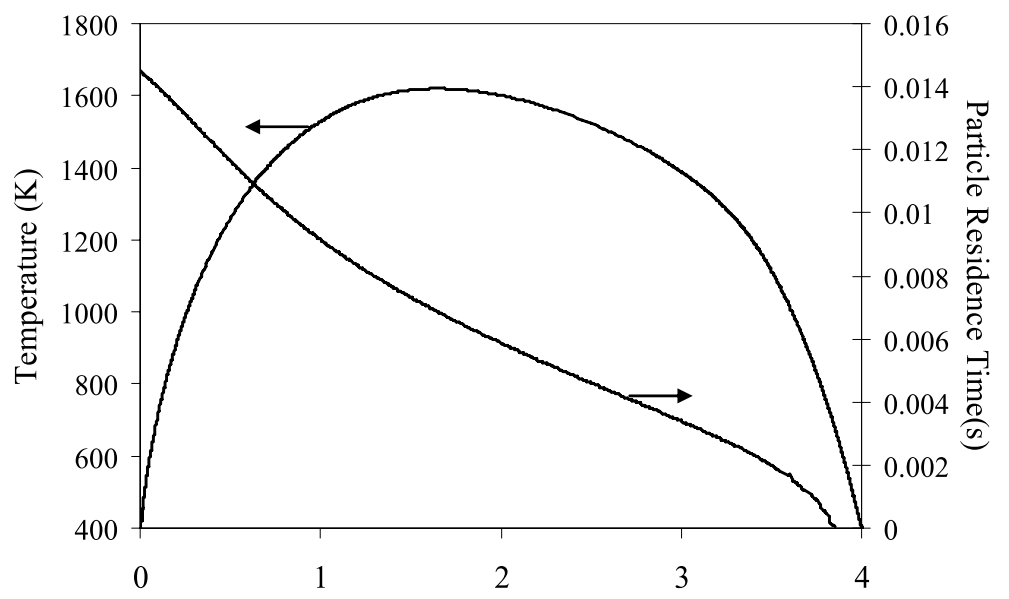

Distance from Substrate $(\mathrm{cm})$

\section{Conclusions}

In situ Raman scattering has been employed to characterize particle crystallinity (e.g. anatase titania, $\alpha$-alumina) and delineate phase conversion within nano-aerosols at high temperatures. The reliability and precision of the technique are demonstrated using a nanoparticle-seeded jet diffusion flame at atmospheric pressure and a nanoparticlesynthesizing premixed stagnation-point flame at low pressure. Concurrent use of gas-phase SRS or LIF provides correlation with local gas-phase temperatures. Ongoing work involves assessing the particle temperature (which may or may not differ from the gas-phase temperature) by using the Stokes/anti-Stokes Raman intensity ratio for the nanoparticles themselves. Combined with other in situ diagnostics, mapping of chemical species concentrations, quantitative determination of thermodynamic properties, and assessment of nanoparticle properties are made possible to properly characterize material processing flow fields. Such explicit information is essential for the modeling of governing mechanisms, along with detailed computational simulation for quantitative realism, fundamental understanding, and predictive capability. Particularly innovative, our diagnostic technique has the potential to be used as an online diagnostic in large-scale synthesis facilities to monitor nanoparticle properties so that process conditions can be actively adjusted through real-time feedback, ensuring highpurity yields of materials with specific user-defined properties. Fundamentally, the technique can be a very useful tool in understanding crystallization kinetics and phase transformation of nanoparticle-based systems.

\footnotetext{
Acknowledgements This work was supported by the National Science Foundation through grants NSF-CTS-0213929 and NSF-CTS0325057, by the Office of Naval Research through grant N00014-081-1029, and by the Army Research Office through grant W911NF-081-0417. Special thanks are due to Dr. Hong Zhao for her help with the computations and to Dr. Geliang Sun and Mr. Hadi Halim for their help with the experiments.
}

\section{References}

1. S.E. Pratsinis, Progr. Energy Combust. Sci. 24, 197 (1998)

2. M.S. Wooldridge, Progr. Energy Combust. Sci. 24, 63 (1998)

3. N.G. Glumac, Y.J. Chen, G. Skandan, J. Mater. Res. 13, 2572 (1998)

4. H. Zhao, X. Liu, S.D. Tse, J. Nanopart. Res. 10, 907 (2008)

5. H. Zhao, X. Liu, S.D. Tse, J. Aerosol Sci. 40, 919 (2009)

6. F. Xu, X. Liu, S.D. Tse, Carbon 44, 570 (2006)

7. F. Xu, H. Zhao, S.D. Tse, Proc. Combust. Inst. 31, 1839 (2007)

8. F. Xu, X. Liu, S.D. Tse, F. Cosandey, B.H. Kear, Chem. Phys. Lett. 449, 175 (2007)

9. F. Xu, S.D. Tse, J.F. Al-Sharab, B.H. Kear, Appl. Phys. Lett. 88, 243115 (2006)

10. P.W. Morrison, R. Raghavan, A.J. Timpone, C.P. Artelt, S.E. Pratsinis, Chem. Mater. 9, 2702 (1997)

11. G. Beaucage, Nat. Mater. 3, 370 (2004)

12. Y. Xing, U.O. Koylu, D.E. Rosner, Appl. Opt. 38, 2686 (1999)

13. D. Mukherjee, A. Rai, M.R. Zachariah, J. Aerosol Sci. 37, 677 (2006)

14. S. Maffi, F. Cignoli, C. Bellomunnoa, S. De Iuliisa, G. Zizak, Spectrochim. Acta, Part B: At. Spectrosc. 63, 202 (2008)

15. L.S. Hsu, C.Y. She, Opt. Lett. 10, 638 (1985)

16. C.R. Aita, Appl. Phys. Lett. 90, 213112 (2007)

17. M.P. Moret, R. Zallen, D.P. Vijay, S.B. Desu, Thin Solid Films 366, 8 (2000)

18. I. De Wolf, Semicond. Sci. Technol. 11, 139 (1996)

19. Z.L. Wang, Characterization of Nanophase Materials (Wiley$\mathrm{VCH}$, New York, 2000)

20. W. Ma, Z. Lu, M. Zhang, Appl. Phys. A: Mater. Sci. Process. 66, 621 (1998)

21. D. Bersani, P.P. Lottici, X.Z. Ding, Appl. Phys. Lett. 72, 73 (1998)

22. M.J. Scepanovic, M. Grujic-Brojcin, Z.D. Dohcevic, Z.V. Popovic, Appl. Phys. A 86, 365 (2007)

23. S.-M. Oh, T. Ishigaki, Thin Solid Films 457, 186 (2004)

24. S.R. Emory, S. Nie, Anal. Chem. 69, 2631 (1997)

25. M.S. Dresselhaus, G. Dresselhaus, G. Saito, R. Jor, Phys. Rep. 409, 47 (2005)

26. D.S. Bethune, G. Meijer, W.C. Tang, H.J. Rosen, Chem. Phys. Lett. 174, 219 (1990)

27. N. Everall, J.B. King, I. Clegg, Chem. Br. 36, 40 (2000)

28. S.K. Sharma, S.M. Angel, M. Ghosh, H.W. Hubble, P.G. Lucey, Appl. Spectrosc. 56, 699 (2002)

29. R.J. Hall, L.R. Boedeker, Appl. Opt. 23, 1340 (1984)

30. R.L. Farrow, R.P. Lucht, G.L. Clark, R.E. Palmer, Appl. Opt. 24, 2241 (1985) 
31. E.J. Davis, G. Schweiger, The Airborne Microparticle: Its Physics, Chemistry, Optics, and Transport Phenomena (SpringerVerlag, Berlin, 2002)

32. A.K. Misra, S.K. Sharma, P.G. Lucey, Lunar Planet. Sci. XXXVI, 1546 (2005)

33. A. Li Bassi, D. Cattaneo, V. Russo, C.E. Bottani, E. Barborini, T. Mazza, P. Piseri, P. Milani, F.O. Ernst, K. Wegner, S.E. Pratsinis, J. Appl. Phys. 98, 074305 (2005)

34. W.F. Zhang, Y.L. He, M.S. Zhang, Z. Yin, Q. Chen, J. Phys. D: Appl. Phys. 33, 912 (2000)

35. C. Pighini, D. Aymes, N. Millot, L. Saviot, J. Nanopart. Res. 9, 309 (2007)

36. T. Ohsaka, J. Phys. Soc. Jpn. 48, 1661 (1980)

37. S.P.S. Porto, P.A. Fluery, T.C. Damen, Phys. Rev. 154, 522 (1967)

38. P.P. Lottici, D. Bersani, M. Braghini, A. Montenero, Appl. Phys. A 28, 177 (1993)

39. Y. Hara, M. Nicol, Phys. Status Solidi B 94, 317 (1979)

40. U. Balachandran, N.G. Eror, J. Solid State Chem. 42, 276 (1982)

41. C.A. Melendres, A. Narayanasamy, V.A. Maroni, R.W. Siegel, J. Mater. Res. 4, 1246 (1989)
42. A. Mortensen, D.H. Christensen, O.F. Nielsen, E. Pedersen, J. Raman Spectrosc. 22, 47 (1991)

43. A. Misra, H.D. Bista, M.S. Navatia, R.K. Thareja, J. Narayan, Mater. Sci. Eng. B 79, 49 (2001)

44. R. Krishnan, R. Kesavamoorthy, S. Dash, A.K. Tyagi, Baldev Raj, Scr. Mater. 48, 1099 (2003)

45. R. Lewis, H.G.M. Edwards, Handbook of Raman Spectroscopy: From the Research Laboratory to the Process Line (Marcel Dekker, New York, 2001)

46. C. Eckbreth, Laser Diagnostics for Combustion Temperature and Species (Gordon and Breach Publishers, New York, 1996)

47. N. Everall, T. Hahn, P. Matousek, A.W. Parker, M. Towrie, Appl. Spectrosc. 55, 1701 (2001)

48. V. Swamy, A. Kuznetsov, L.S. Dubrovinsky, R.A. Caruso, D.G. Shchukin, B.C. Muddle, Phys. Rev. B 71, 184302 (2005)

49. A.J. Rulison, P.F. Miquel, J.L. Katz, J. Mater. Res. 11, 3083 (1996)

50. R.D. Shannon, J.A. Pask, Am. Mineral. 49, 1707 (1964) 